\title{
Ordenamiento y gestión del territorio en zonas costeras con turismo residencial. El caso de Región Este, Uruguay ${ }^{1}$
}

\author{
Land planning and management in coastal zones with \\ second homes. The case of East Region, Uruguay
}

\author{
Isabel Gadino² (10) y Germán Taveira³ (1)
}

\begin{abstract}
RESUMEN
El turismo de sol y playa asociado a la modalidad residencial, es una de las actividades más importantes del Uruguay. Las características de ocupación urbana de las costas de Región Este (departamentos de Maldonado y Rocha) generan desde su inicio impactos de gran magnitud. Entre 1997 y 2003 se crean los dos primeros instrumentos de ordenamiento territorial y gestión, que involucran la defensa, protección y desarrollo sustentable de áreas costeras: la Evaluación de Impacto Ambiental (de aplicación nacional) y la Ordenanza Costera del departamento de Rocha. Se estudian sus resultados a la actualidad, a través de las transformaciones en el territorio y sus impactos socio-ambientales. Mediante análisis cuantitativos, cualitativos y espaciales, se ponen en evidencia aciertos y fallas en la concepción e implementación de dichos instrumentos.
\end{abstract}

Palabras clave: turismo residencial, costa, evaluación de impacto ambiental, ordenamiento y gestión territorial, Uruguay.

\begin{abstract}
Sun and beach tourism associated with residential modality, is one of the most important activities in Uruguay. The urban occupation characteristics of the East Region coasts (Maldonado and Rocha departments) generate from the beginning impacts of great magnitude. Between 1997 and 2003 the first two instruments of land planning and management, involving the defence, protection and sustainable development of coastal areas, were created: the Environmental Impact Assessment (of national application) and the Coastal Ordinance of the department of Rocha. This paper analyzes their current results, through the transformations in the territory and their socio-environmental impacts. By means of quantitative, qualitative and spatial analyses, the successes and failures in the conception and implementation of these instruments are revealed.
\end{abstract}

Keywords: residential tourism, coast, environmental impact assessment, land planning and management, Uruguay.

Este trabajo se enmarca en la tesis Las capacidades de la planificación del territorio frente a las presiones del turismo residencial en la costa de Región Este, Uruguay, desarrollada por I. Gadino en el Doctorado en Medio Ambiente y Sociedad, Universidad Pablo de Olavide - UPO, España. Arquitecta, Magíster en Ciencias Ambientales. Profesora Adjunta en el Departamento de Territorio, Ambiente y Paisaje, Centro Universitario Regional del Este - CURE, Universidad de la República - UdelaR. Correo electrónico: isabelgadino@gmail.com

Licenciado en Gestión Ambiental. Ayudante en el Departamento de Territorio, Ambiente y Paisaje, Centro Universitario Regional del Este CURE, Universidad de la República - UdelaR. Correo electrónico: gantaveira@gmail.com 
Mazón \& Aledo (2005) definen el turismo residencial (TR) como la actividad económica que se dedica a la urbanización, construcción y venta de viviendas que conforman el sector extra hotelero, cuyos usuarios las utilizan como alojamiento para veranear o residir, de forma permanente o semipermanente, fuera de sus lugares de residencia habitual ${ }^{4}$. Con respecto a sus impactos, estos autores plantean que la crisis implícita en el ciclo de vida del turismo, en los casos de TR no sólo se genera por la pérdida de calidad del producto global, sino -particularmente- por el agotamiento del suelo urbanizable (Mazón \& Aledo, 2005). Navarro-Jurado et al. (2015) señalan que el agotamiento de un espacio turístico deviene siempre en el traslado hacia una nueva periferia, y análisis como el de Piñeira Mantiñán \& Santos (2010) o el de Brida et al. (2011) reconocen que este gran consumo de suelo se asocia a usos muy breves.

Como consecuencia del TR aparecen el desplazamiento y la exclusión social, sumados a cambios espaciales locales (van Noorloos, 2013), y un aplastamiento de la lógica de naturaleza local -enlazada al desarrollo sostenible- a favor de la lógica empresarial -netamente económica y cortoplacista- socializando costos y privatizando beneficios (Aledo et al., 2007). Peeters et al. (2018) agregan a esto que los residentes de sitios turísticos enfrentan una degradación o reducción de infraestructura o instalaciones específicas de la comunidad y costos inflados en todo tipo de servicios y productos, además de que la estacionalidad y el empleo turístico puede conducir a una (sobre) dependencia y al decaimiento económico de otros sectores de trabajo. Como principales fuentes de conflicto entre los desarrollos inmobiliarios turísticos y la planificación territorial, Almeida et al. (2017) mencionan la ausencia de una política de uso de la tierra, así como la falta de claridad en las estrategias de conservación de la naturaleza.

Son varios los estudios que ilustran la magnitud actual que el fenómeno está teniendo en zonas costeras de América Latina (Van Noorloos, 2011; Pino Rojas, 2018; García de Fuentes et al., 2019; Pontes, 2020) en donde se constata una expansión sin precedentes en la década de los 2000 (Barrantes-Reynolds, 2011).

Desde los análisis de la geografía crítica sobre la producción del espacio, ya en 1974 Lefebvre identificaba al turismo como la forma en la que el capitalismo avanzaba sobre territorios hasta ese entonces vacantes, al tiempo que asumía la incapacidad del sistema para planificar esta nueva actividad. En la misma línea se encuentran las reflexiones de Harvey (2000) sobre la urbanización como motor de acumulación del capital, incluso por encima de las actividades industriales. Escalera-Briceño et al. (2018) exponen cómo la construcción y reconstrucción de diferentes espacios destinados al turismo, son indispensables para incrementar el productivismo, a la vez que empleadas para la especulación financiera. Cortés Chávez (2009) se refiere a este uso del espacio costero como una forma de ocupación que se presenta "como una expresión territorial del modelo económico, donde la premisa de la explotación, está sobre la protección y conservación, generando la depredación de hábitats de relevancia, y el deterioro del valor ambiental del territorio" (Córtez Chávez, 2009:39).

La literatura anglosajona usa el término "segundas residencias" para analizar un fenómeno con características muy similares al TR, que de acuerdo a Perles Ribes et al. (2018) deberían emplearse como sinónimos. 
En Uruguay el TR está fuertemente vinculado al turismo de sol y playa, actividad económica que se ubica entre las más importantes del país ${ }^{5}$. Desde principios del SXX se refracciona gran parte de las costas Sur (platense) y Este (oceánica) con el propósito de transformar tierras infértiles para la producción agropecuaria de ganadería extensiva, en un proyecto de balneario de casi 300 kms de largo, generando uno de los mayores cambios de uso del suelo del país. Primó entonces el desconocimiento absoluto de las dinámicas naturales o del propio sitio a lotear: la circulación de sedimentos es esencial para la permanencia del sistema de playas arenosas (McHarg, 1969; McGwynne \& MacLachlan, 1992; Ibarra \& Belmonte, 2017), y la geomorfología de estos sitios una vez antropizados, es resultado de la interacción entre procesos naturales y transformaciones humanas (Alcántara-Carrio et al., 2014). Tampoco se observaron a tiempo las consecuencias de afectar la cobertura vegetal natural, fragmentando hábitats preexistentes, lo que significa reducción de superficie, aumento del aislamiento entre parches y mayor exposición a usos antrópicos a lo largo de los bordes (Lindenmayer \& Fischer, 2006), con resultados persistentes, perjudiciales e imprevisibles (Haddad et al., 2010).

EI TR quedó implantado a través de un modelo de desarrollo dedicado a la inversión inmobiliaria, urbanización y venta de viviendas en el sector extra hotelero (Díaz Pellicer, 2012; Da Cunha \& Campodónico, 2012) conformado por más de 70 fraccionamientos cuya génesis y gestión estuvo principalmente a cargo de estancieros y agrimensores. La posibilidad legalmente admitida para balnearios ${ }^{6}$, de retardar la instalación de servicios básicos urbanos como saneamiento e infraestructura para movilidad, fue un factor determinante para este auge fraccionador.

A nivel nacional las consecuencias del proceso de balnearización costera se han evidenciado en numerosas investigaciones: afectación y pérdida de biodiversidad (Klappenbach \& Scarabbino, 1969; Alonso \& Bassagoda, 2002; Soutullo et al., 2013), pérdida de arena seca y en circulación (Gutiérrez, 2016), degradación de la calidad del agua, erosión de playas, retroceso de costa, reducción de capacidad disipadora de la playa y degradación del valor escénico, incrementando la vulnerabilidad a la erosión, limitando y reduciendo el "recurso playa" (Panario, 2000; De Álava, 2007; Gadino, 2012; Boretto et al., 2018); pérdida de sitios arqueológicos (Brum, 2013; Gianotti et al., 2017), entre otros. Panario \& Gutiérrez (2006) confirman la ausencia de una fuente actual de sedimentos de la magnitud necesaria para la recuperación de los campos dunares perdidos por estas acciones, en tanto Alves \& Goso (2015) concluyen que la superficie de los campos de dunas móviles que alimentan las playas, se redujo en un $50 \%$ desde la década de 1960 a la actualidad, mayormente por fijación de las dunas por forestación. Para Achkar et al. (2012) los ecosistemas costeros uruguayos estarán en adelante sometidos a la intensificación del turismo, con amenazas como el incremento de la urbanización, impermeabilización del suelo y grandes obras de infraestructuras, asociados a riesgos de disminución de la biodiversidad, fijación de dunas, erosión de playas, contaminación de agua y cambio de paisaje, con vulnerabilidades como homogeneización de ambientes, pérdida de playas, pérdida de valoración social por las playas y disminución de la calidad del paisaje.

Actualmente el turismo genera -en un país de tan solo 3.5 millones de habitantes- más de 100.000 puestos de trabajo en actividades relacionadas (uruguayxxi.gub.uy). En la temporada 2015-16 ingresaron 1.4 millones de turistas del exterior (Cinve, 2016)

Art. 15, Ley de Centros Poblados de 1946. 
En paralelo, a partir del nuevo paradigma global de desarrollo sustentable, y marcos teóricos asociados como el manejo integrado costero, desde fines de los 90 y principios del 2000 se implementan en el país dos instrumentos que apuntan a la defensa, protección y desarrollo sustentable del ambiente, con distintos énfasis en áreas costeras. El presente artículo tiene como objetivo identificar cuál ha sido su contribución real, sobre impactos ambientales y sociales generados desde entonces por el turismo residencial. Se analizan resultados sobre la dinámica costera (geomorfológica), la conservación del medio natural y la fragmentación socio-espacial en la Región Este, sitio de turismo estival por excelencia en Uruguay?.

\section{Área de estudio}

La zona de estudio abarca la costa de Región Este e involucra a los departamentos Maldonado y Rocha. Tiene 280 kilómetros de largo con frente al Río de la Plata y al Océano Atlántico. El 70\% de esta costa -conformada por playas arenosas entre cabos rocosos, lagunas y humedales asociados- fue fraccionado para balnearios a mediados del SXX, aunque una parte de estos emprendimientos no se consolidó. Desde entonces existe una tensión permanente entre el desarrollo urbano y la conservación de los servicios ecosistémicos que dan soporte al turismo. La expansión también implica la actual transformación de remanentes rurales a urbanos o suburbanos. Sobre este territorio actúan los dos instrumentos a analizar: la Evaluación de Impacto Ambiental (de aplicación nacional) y la Ordenanza Costera del departamento de Rocha, por lo que el área permitirá comparar los resultados de situaciones diferentes de los primeros instrumentos de gestión territorial ambiental con los que contó el país. El ancho de la faja estudiada varía en función de la ubicación de casos y sectores abordados por estas normativas.

\section{Desarrollo histórico de la zona}

El análisis temporal evidencia una consolidación diversa de los fraccionamientos costeros, con algunos tempranamente exitosos hasta otros que a la actualidad no cuentan siquiera con la apertura de calles planificada. La costa maldonadense se levantó casi por completo como balnearia de élites. Este departamento presentó una tasa de crecimiento poblacional 10 veces mayor a la media nacional en el último período intercensal (INE, 2011), con causas directamente vinculadas a las posibilidades laborales que ofrecen los servicios asociados al turismo y la construcción (Rodríguez Miranda et al., 2017). A nivel espacial se observa una fuerte demanda de nuevas áreas para seguir construyendo espacios residenciales lejanos a destinos masificados, y la clara separación entre turismo y población permanente de medios o bajos recursos (Acuña et al., 2013).

La situación es diferente en Rocha, en donde la lejanía a Montevideo y Buenos Aires - históricamente emisoras de turistas e inversores- así como la condición de frente costero más agreste, dejó pendiente la consolidación de la mayor parte de los emprendimientos (IDR, 2010: 8; da Cunha \& Campodónico, 2012). Salvo pocas localidades, en general conformadas por viviendas unifamiliares de clase media, el resto de las playas quedaron deshabitadas por décadas y con el tiempo algunas de ellas fueron ocupadas básicamente en forma espontánea e ilegal, generando

Balance 2017-18 presentado por Ministerio de Turismo, 9/2/18 
importantes casos de asentamientos irregulares de segunda residencia (Capandeguy et al., 2016). Por otro lado, la paralización inmobiliaria le permite contar con grandes superficies de áreas poco antropizadas, otorgándole una condición de naturalidad que la destaca a nivel regional y mundial (Probides, 1999), situación que ejerce como impulsor de conflicto entre aquellos que aspiran a un desarrollo turístico hegemónico y los que ven en estas costas la oportunidad para modalidades alternativas, con énfasis en la conservación de los factores naturales.

En este marco hay dos aspectos nacionales a destacar. El primero es que históricamente en Uruguay la propiedad privada de la tierra básicamente otorga al propietario un uso ilimitado del bien, con pocas restricciones de la sociedad ${ }^{8}$ (Alvarez Lenzi, 1986:18; Piñeiro, 2011:20). El segundo es que, desde la aprobación del Código Civil en 1868, salvo puntuales excepciones, las playas son públicas (Sciandro \& Rabellino, 2014), hecho que, entre otros aspectos, fomenta la preocupación de grupos locales para su conservación (Rodríguez, 2017).

\section{Avances en la normativa}

Históricamente en Uruguay existía normativa ambiental o territorial ${ }^{9}$, generada en forma fragmentada y aplicada de manera escasa o directamente omitida (Urruzola et al., 2011). Siguiendo tendencias mundiales, en 1990 se crea el Ministerio de Vivienda, Ordenamiento Territorial y Medio Ambiente (MVOTMA), y en un lapso de diez años se aprueban las dos leyes objeto de este estudio. Algunas definiciones y estrategias del antiguo corpus son retomadas por esta legislación, como el concepto de línea de ribera (LDR) -trazada a partir del promedio de las máximas alturas registradas cada año durante un período no menor de veinte años- y las fajas de protección medidas a partir de ésta: la no urbanizable de $150 \mathrm{mts}^{10}$ y la de defensa costera de $250 \mathrm{mts}^{11}$ que evita modificaciones perjudiciales a su configuración y estructura.

La primera ley estudiada en este trabajo es la 16.466 de Medio Ambiente de 1994, que declara de interés general y nacional la protección del medio ambiente contra cualquier tipo de depredación, destrucción o contaminación, así como la prevención del impacto ambiental negativo o nocivo, y en adelante la recomposición del medio ambiente dañado por actividades humanas. Como instrumento asociado se establece la Evaluación de Impacto Ambiental ${ }^{12}$ (EIA), procedimiento técnico-administrativo y preceptivo que sirve para identificar, prevenir o interpretar los potenciales impactos de determinados proyectos o acciones ${ }^{13}$. De ellos, los que directamente se relacionan con este trabajo son las construcciones que se proyectan en la Faja de Defensa Costera (FDC) de $250 \mathrm{mts}$. El primer paso que exige la EIA es obtener la autorización ambiental previa (AAP), presentando cada proyecto al MVOTMA, indicando posibles impactos ambientales de la obra y una auto categorización como A (sin impactos significativos), B (con impactos moderados y controlables) o $C$ (con impactos negativos significativos). El Ministerio estudia y decide la categoría final: A puede llevarse a cabo en las condiciones presentadas. B o C indican la necesidad

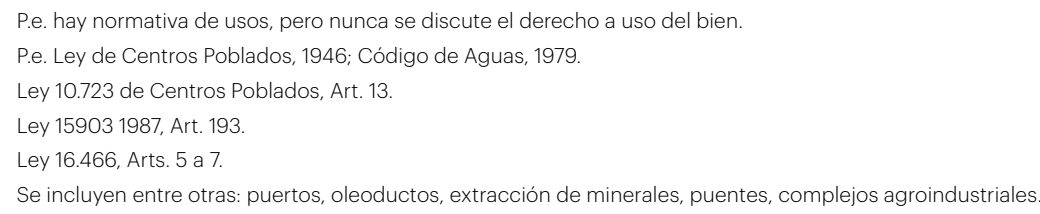


de un Estudio de Impacto Ambiental (Es|A), realizado a costo del proponente, por técnicos que integran la lista autorizada por el MVOTMA.

Es importante mencionar que sobre el concepto y uso de este instrumento se observan cuestionamientos tanto a nivel internacional como nacional (Treweek, 1996; Berazategui et al., 2012; Ligrone, 2017). Entre ellos, Gudynas (2004) señala que esta primera generación de normativas ambientales responde básicamente a cuestiones técnicas de gestión y gerenciamiento, sin alcanzar la fase de creación de políticas nacionales sobre el tema.

En 2003 Rocha aprueba el Plan de Ordenamiento y Desarrollo Sustentable de la Costa Atlántica, conocido comúnmente como Ordenanza Costera (OC). Entre sus principios destacamos: i) la conservación en un alto grado de naturalidad de su ribera oceánica conciliando las exigencias de desarrollo con los imperativos de protección y ii) que el derecho de construcción y de alteración de las características y condiciones naturales del suelo, en suelo de dominio privado, debe atender al interés general. A nivel espacial la OC retoma la Faja de Exclusión de $150 \mathrm{mts}$. paralela a la costa y la declara no urbanizable ni edificable. También aplica el concepto de FDC de $250 \mathrm{mts}$. al que se le suma una Zona de Interfase a definir por sectores, cuya finalidad principal es procurar "una baja densidad de ocupación del suelo y asegurar la accesibilidad de la Ribera Marítima" (Art 12). Transversalmente, plantea una zonificación estratégica para diversificar la oferta turística. De esta forma se identifican entre otras áreas: de Desarrollo Urbano Turístico; de Urbanización Concertada; y de Turismo de Baja Intensidad. En la primera se establece que se concentrarán esfuerzos en inversiones públicas para consolidación y mejora del área urbana, enfatizando en que sean concordantes con los principios de uso sustentable. La segunda categoría identifica "fraccionamientos con escaso grado de consolidación [...] en los que aún se está a tiempo de promover un desarrollo turístico sustentable de acuerdo con los principios de conservación de la naturalidad de la costa, baja ocupación, protección del valor paisajístico y ambiental" (Art 19.1). La tercera consiste en espacios de la costa con escasa o ninguna consolidación, sin población, edificaciones, servicios ni equipamientos, en las que se propenderá a "revertir la situación actual de fraccionamiento del suelo en predios de áreas menores, tendiendo al reparcelamiento en predios que tengan como mínimo 5 hectáreas" (Art 20.4).

Pocos años después, en 2008, comienza un nuevo capítulo a nivel de normativa nacional, con la aprobación de Ley de Ordenamiento Territorial y Desarrollo Sostenible (LOTDS), la que enmarca y refuerza los dos instrumentos descritos, además de incorporar, entre otros, la importancia de la participación ciudadana en la planificación territorial.

\section{Materiales y métodos}

El propósito de este trabajo es contrastar los objetivos de los instrumentos analizados, con sus resultados en el territorio. Para ello se aborda el problema desde múltiples dimensiones. Se entrecruzan información secundaria abierta de solicitudes y comunicaciones de autorizaciones ambientales, información censal, capas de información geográfica, imágenes satelitales, páginas de promoción turística y datos de salidas a campo (Cuadro $\mathrm{N}^{\circ} 1$ ). Se realiza un análisis cuantitativo y cualitativo que permite observar diferentes etapas y aspectos implicados, entrelazamientos y consecuencias. 
Cuadro No1.

MATERIALES Y MÉTODOS

\begin{tabular}{|c|c|c|c|}
\hline TEMA & FACTOR & MATERIALES & MÉTODOS \\
\hline \multirow{6}{*}{$\begin{array}{l}\text { DINÁMICA } \\
\text { COSTERA }\end{array}$} & Cantidad casos & $\begin{array}{l}\text { Autorización ambiental } \\
\text { Previa (AAP) }\end{array}$ & Tablas asociadas a capas SIG \\
\hline & $\begin{array}{l}\text { Categoría } \\
\text { autopropuesta y final }\end{array}$ & AAP & Tablas asociadas a capas SIG \\
\hline & Ubicación casos & AAP & SIG e imagen satelital \\
\hline & $\begin{array}{l}\text { Agrupación/dispersión } \\
\text { de casos }\end{array}$ & Imágenes satelitales & $\begin{array}{l}\text { Mapa de Calor sobre imagen } \\
\text { satelital }\end{array}$ \\
\hline & $\begin{array}{l}\text { Distancia a línea de } \\
\text { ribera (LDR) }\end{array}$ & $\begin{array}{l}\text { Estudios de Impacto } \\
\text { Ambiental (EsIA) e } \\
\text { imágenes satelitales } \\
\text { históricas }\end{array}$ & $\begin{array}{l}\text { Descripciones y proxy línea de } \\
\text { ribera }\end{array}$ \\
\hline & Descripción presentada & EsIA & Extracción de fragmentos \\
\hline \multirow{5}{*}{$\begin{array}{l}\text { MEDIO } \\
\text { BIÓTICO }\end{array}$} & Cantidad casos & Salidas a campo & Tablas asociadas a capas SIG \\
\hline & Ubicación casos & AAP & Tablas asociadas a capas SIG \\
\hline & $\begin{array}{l}\text { Agrupación/dispersión } \\
\text { de casos }\end{array}$ & AAP & SIG e imagen satelital \\
\hline & $\begin{array}{l}\text { Fragmentación y } \\
\text { sustitución de hábitats }\end{array}$ & $\begin{array}{l}\text { Imagen satelital y } \\
\text { relevamientos in situ }\end{array}$ & $\begin{array}{l}\text { Observación del predio y } \\
\text { zonas aledañas }\end{array}$ \\
\hline & Descripción presentada & EsIA & $\begin{array}{l}\text { Lectura de resúmenes oficiales } \\
\text { disponibles. }\end{array}$ \\
\hline \multirow{3}{*}{$\begin{array}{l}\text { FRAG. } \\
\text { SOCIO } \\
\text { ESPACIAL }\end{array}$} & $\begin{array}{l}\text { Crecimiento de áreas } \\
\text { para el turismo }\end{array}$ & $\begin{array}{l}\text { Datos vectoriales y } \\
\text { marco censal (INE, } \\
\text { 2011) }\end{array}$ & $\begin{array}{l}\text { Comparación intercensal } \\
\text { viviendas ocupadas/ } \\
\text { desocupadas, ubicación, Jenks }\end{array}$ \\
\hline & $\begin{array}{l}\text { Reducción de visuales } \\
\text { y accesos }\end{array}$ & Relevamientos in situ & $\begin{array}{l}\text { Recorrida y relevamiento } \\
\text { fotográfico }\end{array}$ \\
\hline & Perfil del usuario & $\begin{array}{l}\text { Sitios web de } \\
\text { inmobiliarias }\end{array}$ & Extracción de fragmentos \\
\hline
\end{tabular}

Fuente: Elaboración propia.

Para analizar los impactos en la dinámica costera y el medio natural: se estudia la cantidad de AAP relacionados al TR en la zona costera, porcentajes de auto calificación propuesta y calificación final otorgada por MVOTMA ${ }^{14}$. Dado que este ministerio procesa las AAP contemplando las ordenanzas departamentales, se asume que la calificación final otorgada, es el resultado de la superposición de la ley nacional y la departamental correspondiente. Se cuantifican las categorías A, B o C auto-propuestas y las otorgadas, explorando porcentajes de cada categoría, su relación

14 Datos de la capa de información geográfica Comunicación de Proyectos, Observatorio Ambiental Nacional - MVOTMA, accedido el 30/7/19 
con el período pre y post LOTDS (1994-2008 y 2009-2019) y su superposición con la normativa departamental. Los mismos datos se analizan espacialmente, empleando el programa QGIS 2.18. Se utiliza la herramienta Mapa de Calor como método de representación para analizar la concentración de proyectos, y se observan los puntos sobre imágenes satelitales actuales para revisar la colmatación (dentro de la mancha urbana existente), extensión (apertura de sectores del fraccionamiento sin consolidar) o dispersión de la mancha urbana (proyectos en fraccionamientos sin consolidar o nuevos fraccionamientos).

Debido a que la LDR es una construcción conceptual que tiene por objeto fijar en el espacio un elemento dinámico que es la orilla del mar, y que a nivel nacional esa línea se define para cada proyecto a partir del 0 Warton establecido hace varias décadas, en este trabajo se emplea el proxy arena seca/arena húmeda (Gutiérrez, 2016). En base a éste se comparan imágenes satelitales de series históricas de Google Earth, para corroborar la distancia de una serie de AAP a la LDR en dos fraccionamientos recientes en Maldonado ${ }^{15}$ y cinco viviendas en Rocha ${ }^{16}$. Para cada emprendimiento se emplean las imágenes disponibles del período 2004-2019 a una escala de 1:4.000. En cada caso se parte de la imagen más reciente y sobre ella se traza una línea de $150 \mathrm{mts}$ perpendicular a la costa desde cada vivienda hacia el mar, replicándose en las fotografías históricas del sitio.

Asimismo, se realiza un análisis del contenido de los 21 resúmenes oficiales de EsIA de TR sobre la FDC, también disponibles en la página oficial ${ }^{17}$. Se revisa la información sobre cómo y qué se declara de las afectaciones a la dinámica costera y al medio biótico, y datos acerca de la distancia a la LDR. Se compara este contenido con lo expresado en la normativa y recomendaciones científicas sobre estos factores.

En las salidas de campo en diversos sectores del área (desde Solís a Punta Rubia) se observa: i) el estado de dinámica y hábitats de los sectores afectados por AAP con respecto a la literatura estudiada, ii) las características de las construcciones realizadas con respecto a lo establecido en la normativa y/o lo asumido en los resúmenes oficiales (p.e. sobre elevación con respecto al terreno, apantallamiento en la visual a la costa) y iii) el grado de alteración del entorno de las viviendas construidas (muros, pavimentación, jardinería, sistemas de riego, desagües visibles hacia la costa, alteración del cordón dunar externo al predio). Este componente también se nutre de información proveniente de sitios web de promoción de emprendimientos e imágenes satelitales.

Para estudiar el nexo con la fragmentación socio-territorial: se emplean los datos sobre viviendas ocupadas por zona censal de los censos nacionales 2004 y 2011, llevados a cabo fuera de la temporada estival ${ }^{18}$, por lo que sus resultados reflejan períodos de baja temporada. Para cada censo se estratifican los datos según el método de clasificación por quiebres naturales de Jenks, minimizando la varianza intraclases y maximizando entre clases. Este análisis permite observar si aumenta la separación entre ciudad permanente (interior) y ciudad balnearia (costera) en Maldonado, y si este

\footnotetext{
Mar Azul y Bahía Vik.

Los Botes, Arachania, Punta Rubia, Aguas Dulces y Punta del Diablo.

Manifiestos de Ambiente - MVOTMA. URL: https://www.mvotma.gub.uy/participacion-ciudadana-ambiente/manifiestos-de-ambiente. El número de ítem es el único identificador presente en todos los EsIA: 10002996, 10003060, 10003061, 10003121, 10003454, 10003517, 10004397, 10006653, 10008026, 10008051, 10008067, 10008171, 10010128, 10010318, 10010371, 10010321, 10011182, 10011697, 10012006, 10012334 y 10012380.

18 Los censos se llevaron a cabo entre junio y julio de 2004 y entre setiembre y diciembre de 2011
} 
fenómeno existe también en Rocha. También se estudian los contenidos de los resúmenes oficiales y sitios web de promoción de inmuebles en diversos balnearios, en busca de información acerca del perfil de ocupantes esperados. Las salidas a campo sirven para observar las posibilidades o dificultades de acceso a la playa que generan estas viviendas, así como la calidad constructiva de la construcción y su entorno, que permiten inferir el sector socioeconómico propietario.

Para analizar la concepción y aplicación de los instrumentos normativos: en el caso de la EIA, se estudia la información solicitada (pertinencia de los ítems) y la presentada (análisis interdisciplinar, coherencia interna y externa de los datos), así como la comparación entre el contenido de los informes y/o la ubicación de los proyectos aprobados y la calificación final otorgada. Con respecto a la OC se comparan los resultados obtenidos con los objetivos trazados por franja territorial y sector.

\section{Resultados}

Sobre Impactos en la dinámica costera: para el período 1994-2019 se constatan 445 AAP en la zona estudiada. En la fase de autoevaluación el $95 \%$ de los casos se categoriza como A, un $2 \%$ como B y un $0.5 \%$ como C. No hay datos del $2 \%$ restante. Finalmente, del MVOTMA sale un $86 \%$ de casos A como calificación final, $12 \%$ B y $2 \%$ C. La mayoría de los expedientes A y B finalmente aparecen construidos, no así los C. De los 445 , el $56 \%$ fue evaluado en el primer periodo (199408) y el $42 \%$ en el segundo (2009-19), en $2 \%$ de los casos no hay información de fecha. Esto da un promedio de 18 y 19 casos al año respectivamente, aunque hay grandes variaciones como indica la Figura $\mathrm{N}^{\circ} 1$, fácilmente asociables a crisis económicas regionales y mundiales ${ }^{19}$. A nivel departamental se nota una importante disminución de casos pre y post LOTDS en Rocha (pasan del 31 al $19 \%$ ), no así en Maldonado (25 al 23\%).

Figura $\mathrm{N}^{\circ} 1$.

Cantidad de AAP presentadas por año hasta el año 2018 (años completos).

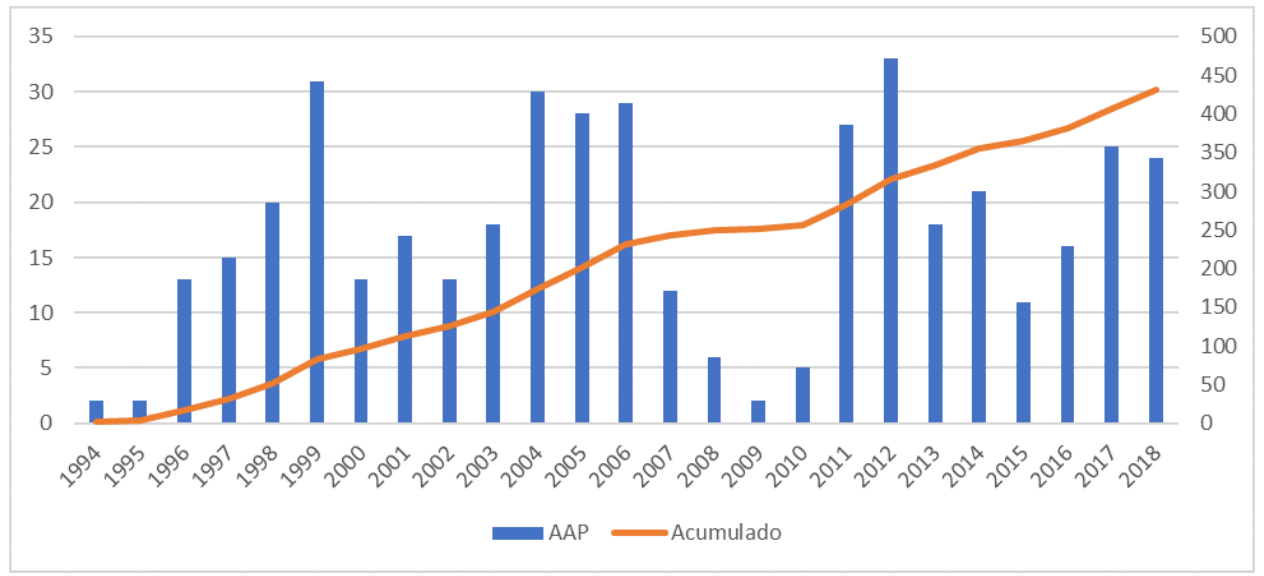

Fuente: Elaboración propia.

Las bajas coinciden con períodos de crisis económica en la región, que afectan particularmente a Argentina entre los años 2001 y 2002 , y el de 2009 con la crisis global surgida unos años antes a raíz del colapso inmobiliario en EE. UU. 
Respecto a la calificación final otorgada -preponderantemente A en ambos períodos- hay una disminución de estos casos luego de la LOTDS (95\% a 73\%), acompañada de un importante aumento en la categoría B ( $3 \%$ a $24 \%$ ) y un pequeño aumento en C ( $2 \%$ a $3 \%$ ). Esta diferencia también se marca al separar las calificaciones por departamento: la superposición de las calificaciones otorgadas pre y post LOTDS, muestra que la disminución de calificaciones $\mathrm{A}$ en el segundo período, es $11 \%$ más acentuada en Rocha que en Maldonado (Figura $N^{\circ} 2$ ).

Figura $\mathrm{N}^{\circ} 2$.

Porcentaje de calificaciones por departamento y por período (pre y post LOTDS).

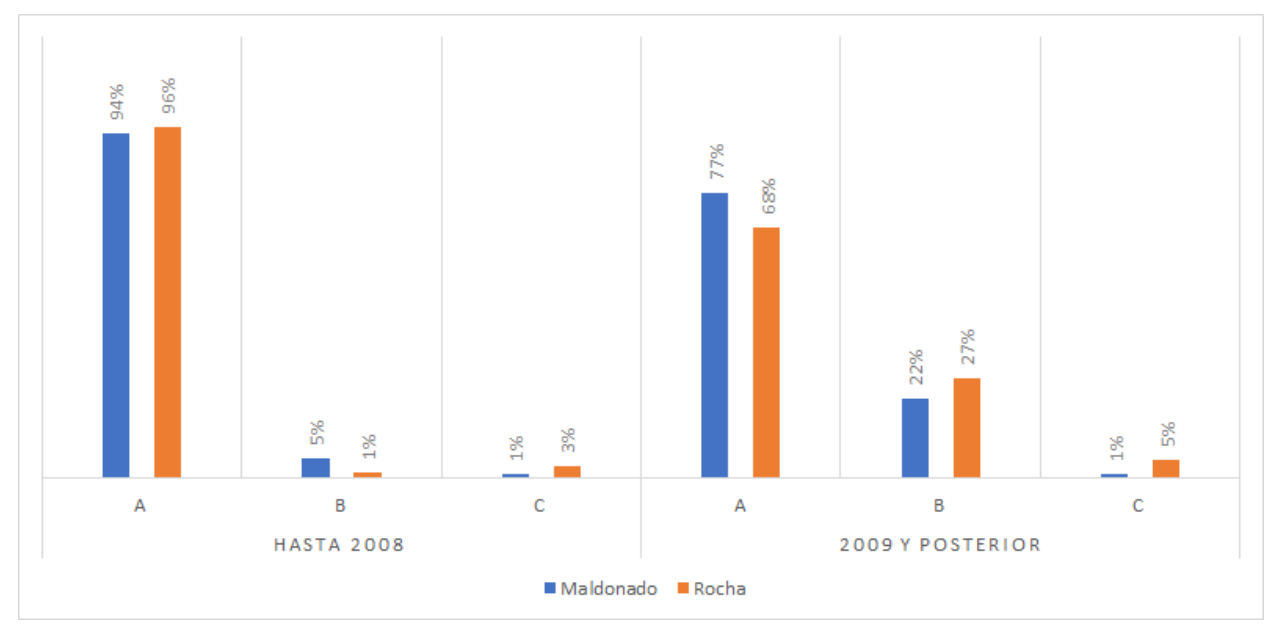

Fuente: Elaboración propia.

El mapa de calor (Figura $\mathrm{N}^{\circ} 3$ ) arroja una gran concentración de AAP en Maldonado en al menos cuatro zonas a lo largo de la costa, con primacía en José Ignacio (54 casos). En el caso de Rocha, la distribución es menor, formando dos áreas de concentración que corresponden a la localidad de Punta del Diablo (71), y a otra zona conformada por un conjunto de balnearios con centro en Punta Rubia-Santa Isabel (37).

En Rocha la superposición de este mapa y la sectorización de la OC marca una relación importante entre las Áreas de Desarrollo Urbano y las AAP. Las imágenes satelitales de estas zonas revelan que los proyectos forman parte de la colmatación, pero sobre todo de la extensión de los fraccionamientos en zonas litorales activas.

La dispersión está más presente en Rocha, debido a la existencia de grandes áreas sin consolidar. Sin embargo, esta modalidad también se observa en Maldonado en la medida que recientemente se han categorizado como urbanos antiguos predios rurales costeros, e incluso ex espacios públicos, ya sea por transacciones directas de la IDM o por juicios llevados a cabo por descendientes de antiguos propietarios (Robaina, 2017).

Sobre la LDR, si bien la normativa prohíbe los nuevos fraccionamientos en los $150 \mathrm{mts}$ de FDC, y la edificación en esa área en Rocha, las imágenes usadas para analizar este tema (período 2004-2019 en distintos meses del año y bajo condiciones diferentes de energía del mar) indican 
Figura $\mathrm{N}^{\circ} 3$.

Concentración de AAP en región este.

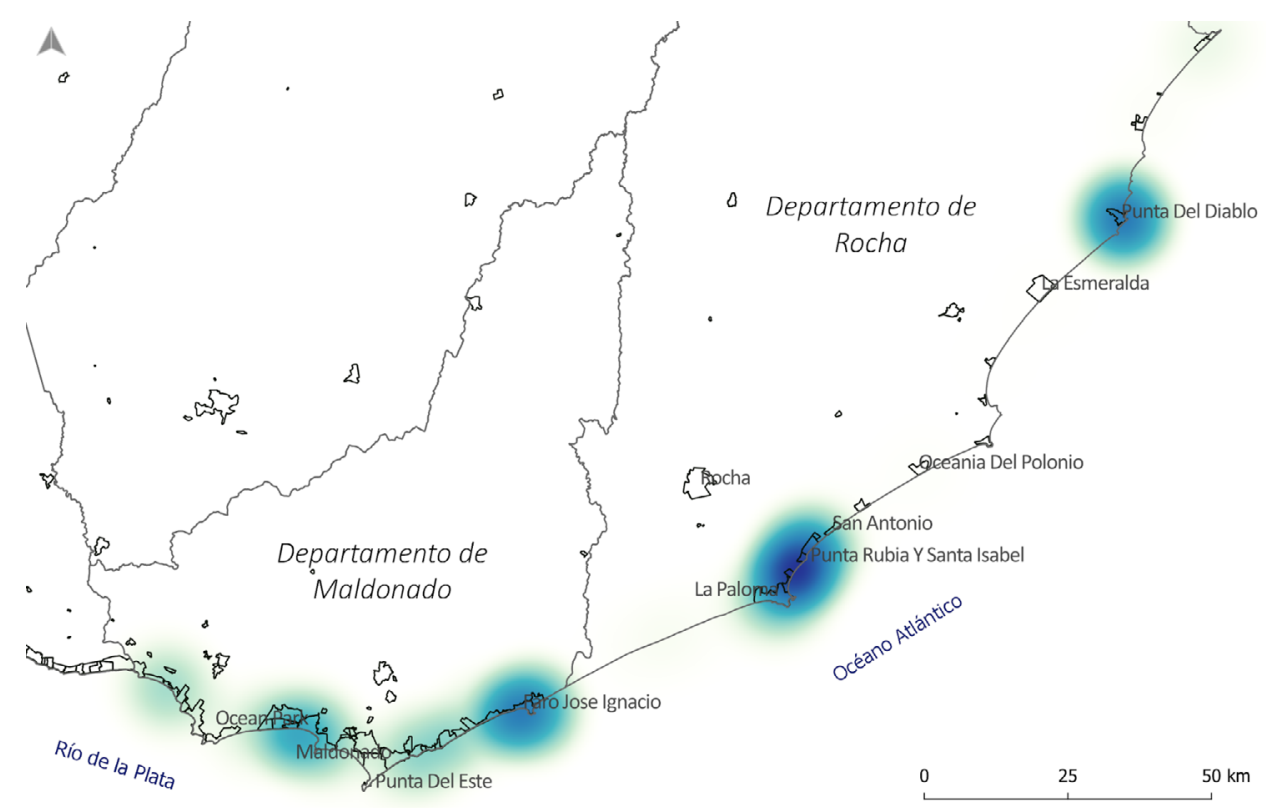

Fuente: Elaboración propia.

que en ningún caso se cuenta con 150 mts entre los emprendimientos y la línea de costa, estando generalmente muy por debajo de la distancia exigida.

El análisis cualitativo de los resúmenes oficiales demuestra desconocimiento, desvalorización u ocultamiento de información pertinente. Sobre la afectación a la dinámica costera se encuentran explicaciones exhaustivas empleando reconocidos marcos teóricos sobre la zona litoral activa, los que no se reflejan en el análisis de los impactos producidos. Así como se descarta por completo el impacto acumulado por la suma de proyectos, el proponente usa este argumento para reforzar su derecho a construir: se apela al nivel de alteración existente del medio y el paisaje para seguir modificándolo, sin asumir que en Uruguay las costas poco o muy antropizadas son el único recurso de playa que existe.

La información científica que analiza el impacto de la fijación de dunas se coloca fuera de contexto, empleando solamente el dato de que las dunas ya están fijas, lo que sirve para argumentar que no habrá mayores impactos con una nueva construcción sobre ellas.

Sobre la faja de exclusión se constatan al menos tres informes de un nuevo fraccionamiento en José Ignacio, que describen que las construcciones se realizarán a una distancia menor a la exigida. Más comprometida es la situación del emprendimiento lindero construido en 2010, con edificaciones que avanzan hasta $80 \mathrm{mts}$ hacia la costa, lo que las deja completamente inmersas en la faja de exclusión. (Figura ํ4). 
Figura $\mathrm{N}^{\circ} 4$.

AAP en nuevos fraccionamientos: con círculo las que se declaran a menos de $150 \mathrm{mts}$ de la LDR. Sobre la derecha el complejo que duplica su acercamiento.

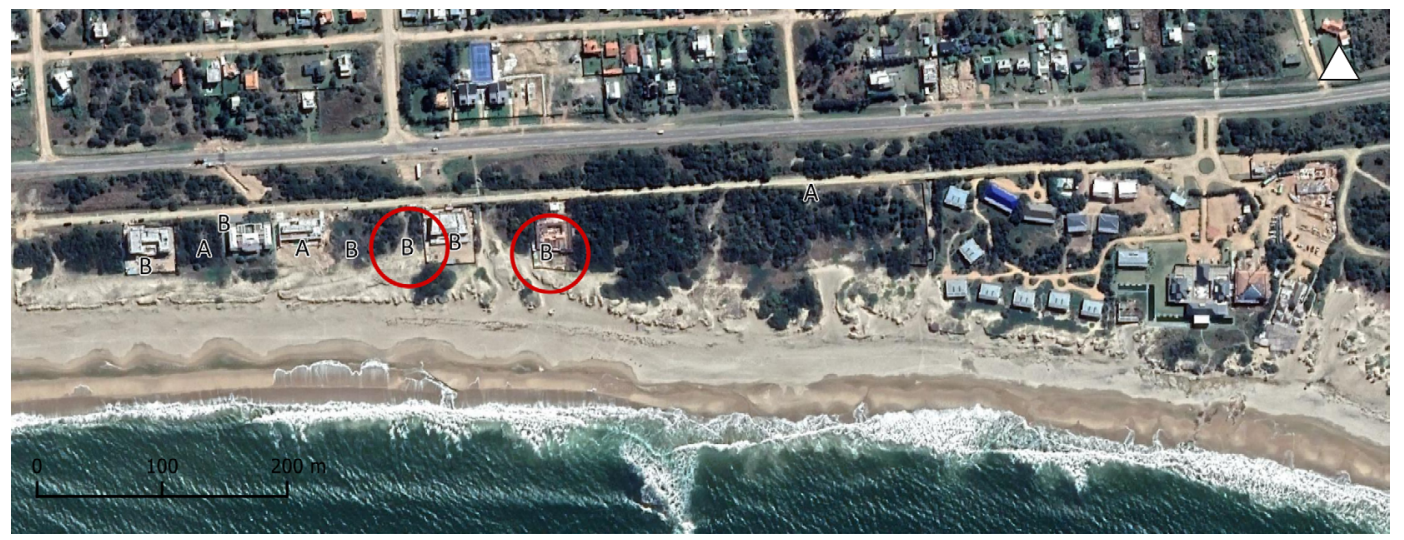

Fuente: Elaboración propia sobre Google Earth.

Respecto al medio biótico, los EsIA analizados muestran carencias importantes, y de igual forma que en aspectos relacionados a la dinámica costera, aparece información errónea, contradictoria o minimizada. Por ejemplo, nunca se considera la reducción de hábitats como factor a tener en cuenta y se asume que nada de lo que hay es endémico del propio predio, 0 , la característica fundamental de la vegetación psamófila que es la de no cubrir la arena, es interpretada como negativa por su escasez. El análisis de imágenes satelitales y las salidas a territorio en diversos sectores comprueban la intensa transformación de los espacios abiertos, que, a pesar de lo declarado en los resúmenes oficiales, en general se pavimentan y tapizan con vegetación alóctona (incluso al lado de una franja declarada oficialmente como patrimonial por ser uno de los últimos relictos de vegetación psamófila del Uruguay). En algunas zonas de gran poder adquisitivo como Portezuelo (Maldonado), se evidencia la apropiación de privados de parte de la playa pública contigua a su predio. Otro factor relativo a la fragmentación, es que muchas de las viviendas observadas frentistas a la costa generan salidas directas a la playa, por lo que el impacto de entradas peatonales en el frente arenoso no se reduce solamente a las calles abiertas, sino que a esto se suman cientos de accesos privados que no son declarados en las EIA. También se encontraron decenas de desagües de pluviales de jardín hacia el cordón dunar.

En base a lo analizado hasta ahora, al comparar las calificaciones de AAP con las fechas, ubicación, contenidos de los informes, transformación real de predios e impacto acumulado, se entiende que la EIA no está cumpliendo efectivamente con sus objetivos. Los casos (construcciones y transformación predial) evidencian un alto grado de fijación de áridos y sustitución de ecosistemas, situación que se da tanto en colmatación de balnearios consolidados, en manchas de extensión de éstos o dispersa en zonas apartadas.

En este contexto, tanto la aprobación de la OC como de la LOTDS parecen ser factores determinantes en los porcentajes por categoría otorgada.

Mientras en la zona costera de Maldonado, de acuerdo con su normativa edificatoria (TONE, 1998) el Factor de Ocupación del Suelo (FOS) se encuentra entre $50 \%$ y $20 \%$, en Rocha, siguiendo 
el modelo territorial de la OC, encontramos sectores con un FOS de $60 \%$ en algunas zonas de Desarrollo Urbano a $1 \%$ en áreas de Turismo de Baja Intensidad. Es claro que en estos sectores el impacto de la construcción es mucho menor en reducción de hábitats o en explotación del recurso playa en temporada, por ejemplo. Sin embargo, el cuidado por reducir áreas construidas no redunda en atención a otros elementos que ayudarían a los objetivos trazados por la OC. El estudio del caso de la zona de Desarrollo Urbano Concertado San Antonio, donde se estimulan refraccionamientos con predios mayores a los existentes, presenta una triplicación (de 9 a 26 casos) de viviendas sobre el espacio que corre entre la última calle abierta paralela al mar y la costa, con formas de ocupación que no denotan adaptarse al cuidado del medio donde se insertan. En el sector de Turismo de Baja Intensidad Oceanía del Polonio, se observan solamente un par de casos de EIA. El estudio de las construcciones da cuenta de la adecuación a la construcción sobre palafitos, pero la visión global del balneario evidencia que sólo 30 de los 2171 lotes ubicados en la zona forestada están ocupados, mientras que, de los 175 predios de las manzanas de la primera línea, mayoritariamente en zona dunar, hay ocupados 16.

La fragmentación socio espacial aparece más claramente en Maldonado, donde la situación de dos tipos de ciudad diferentes -una temporal a lo largo de casi toda su costa, y una permanente bordeando tierras adentro a la anterior- estaba ya consolidada para mediados de 1990, se observó también en 2004 (Acuña et al., 2012; Trochon 2017), y continúa profundizándose en la actualidad. En Rocha aún existen grandes distancias entre las zonas censales costeras, pero esta característica va desapareciendo a medida que se consolidan las urbanizaciones otrora planificadas. En general se aprecia una extensión fundamentalmente turística, además de un incipiente incremento de viviendas vacías en los centros consolidados. Por otro lado, la planificación ambiental sectorizada de la OC que plantea la reagrupación de lotes en padrones mayores para disminuir la fragmentación original, refuerza el uso exclusivo de las playas más prístinas por parte de los propietarios con mayor poder adquisitivo.

Sobre la concepción y aplicación de los instrumentos estudiados se observa en la EIA: el mismo informe se pide para todos los proyectos a ser evaluados en el país -que incluyen desde plantas de celulosa hasta carreteras- lo que obliga al análisis de datos sin ningún sentido para el caso de viviendas en la FDC (como emisión de gases o impacto en la etapa de abandono) y a la vez, permite al proponente desviar la atención de aspectos no favorables. La falta de especificidad desde el inicio del trámite se ve aumentada por datos irrelevantes que el equipo técnico presenta (p.e. el uso de capas de información geográfica de ecosistemas amenazados realizadas a escala 1:50.000, inservible para analizar la situación predial). Esta situación facilita la baja importancia otorgada a temas como la afectación de la vivienda una vez construida, o su impacto acumulativo, revelando un desaprovechamiento de oportunidades para analizar aspectos fundamentales para la conservación del sitio. Los informes presentados por los equipos consultores demuestran grandes carencias u omisiones de conocimiento de aspectos tratados, falta de visión integrada del sistema socio ecológico a modificar e incapacidad de conectar aportes de las diferentes disciplinas intervinientes. También se observa la repetición de estas fallas, en documentos elaborados para distintos casos, desde las mismas firmas consultoras.

Sin dejar de reconocer su gran contribución, la OC tiene aspectos a mejorar: en algunos sectores realiza importantes aportes, pero no está evitando la formación de pantallas visuales en áreas de Desarrollo Turístico, favorece la sobrecarga de las playas adyacentes a dichas áreas y profundiza la fragmentación socio espacial en áreas de mayor conservación. 


\section{Discusión}

Existe una clara línea de desarrollo urbano costero destinado al TR, originada hace casi un siglo con base en el fraccionamiento y multiplicación exponencial de la propiedad privada del suelo, sobre un ecosistema otrora considerado inútil desde todo punto de vista. A pesar de los evidentes impactos socio ecosistémicos negativos, este proyecto urbanizador sigue vigente en miles de lotes que aún permanecen agrestes.

Las búsquedas globales de un desarrollo sustentable, a nivel nacional han dado origen a la aprobación de nuevas instituciones, normas e instrumentos de gestión. Desde entonces se observa una puja entre aquel modelo planificado a principios del SXX y los requerimientos que surgen del nuevo paradigma, tanto como de los impactos constatados.

La evidencia demuestra que el caso analizado presenta grandes similitudes con otros países y regiones (p.e. Aledo et al., 2007; Pino Rojas, 2018) en donde el TR es un factor determinante sobre la costa. Como en otros sitios, se comprueban importantes impactos ecosistémicos en zonas cada vez más extendidas, que en el SE uruguayo se asocian a la modificación de los ciclos locales de movimiento de arena, tanto como a la fragmentación o eliminación de los hábitats asociados. Ambos componentes contribuyen a la vulnerabilidad y pérdida de resiliencia de todo el sistema natural y cultural que soporta al TR, mientras se favorecen lógicas económicas cortoplacistas. Por otro lado, debido a la reducida población nacional, el éxito comercial depende en gran medida de la llegada de turistas e inversiones extranjeros, lo que deja al territorio y sus pobladores en condición de alta vulnerabilidad asociados a procesos socio-económicos regionales e internacionales.

Simultáneamente, se observa un aumento de la segregación socio espacial, en la medida que el TR se consolida en el frente costero de áreas urbanas y sitios menos antropizados, incluso tomando espacio público sobre la costa. A diferencia de otros ejemplos (p.e. Van Noorloos, 2013; Barrantes-Reynolds, 2011) no existen aquí grandes desplazamientos poblacionales, ya que el territorio bajo presión fue en su mayoría, previamente de uso agropecuario extensivo, pero la condición pública de las playas promueve la movilización de la sociedad civil en pro de su conservación.

En el análisis de la EIA se verifican cuestionamientos realizados sobre su forma y alcance (p.e. Berazategui et al., 2012; Ligrone, 2017). El contenido de los informes, así como las construcciones admitidas cuestionan los criterios empleados para avalar equipos técnicos, así como para otorgar los permisos en cada caso. Un factor cuya publicación resulta crucial para el monitoreo y la participación de actores involucrados, es la información geográfica acerca de dónde traza el Estado la LDR, ya que de ella parten dos ámbitos de exclusión y cuidados específicos del territorio.

Por otra parte, la OC realiza aportes constatables hacia el alcance de sus objetivos. Sin embargo, pone en evidencia la existencia de sólo dos escenarios posibles de desarrollo local frente al modelo territorial heredado del SXX: la fragmentación completa en pequeños lotes para el acceso a gran parte de la población, o la agregación en predios mayores para usos exclusivos de sectores pudientes, en pro de una asumida conservación.

Los resultados demuestran que la aplicación de los instrumentos analizados, de distinto orden jerárquico y escala espacial, son insuficientes para la preservación de factores imprescindibles 
para el medio que protegen, así como para impulsar un modelo donde el interés común prevalezca por sobre el privado. Las acciones privadas, avaladas por las políticas públicas, son causa de graves perjuicios ambientales en bienes y servicios comunes. Estas acciones también perjudican finalmente a los permisionarios y a otros propietarios del mismo sistema litoral. En este contexto, la articulación de la EIA con la OC y la LOTDS, parecen mejorar los resultados, pues limitan la calificación de las aprobaciones o mantienen espacios con menor modificación.

Con posterioridad a estas normas se han aprobado planes locales, y recientemente se han invertido muchos recursos en la actualización de información geográfica de todo el país ${ }^{20}$, pero la ampliación de instrumentos y herramientas necesita del análisis profundo y desde diversas perspectivas de sus supuestos y desempeño. Claridad de objetivos de las políticas aprobadas; importancia de los instrumentos desde ámbitos públicos y privados; logros y fallas en cada etapa; capacidad técnica instalada para su cumplimiento, transparencia en los procesos; posibilidad real de monitoreo o en qué medida el tema se abre a la participación pública; son aspectos claves a mejorar.

\section{Referencias bibliográficas}

ACHKAR, M; BLUM, A; BARTESAGHI L; Y CERONI M. Escenarios de cambio de uso del suelo en Uruguay. Informe Técnico. Convenio MGAP/PPR Facultad de Ciencias/Vida Silvestre/ Sociedad Zoológica del Uruguay/CIEDUR, 2012, 24 p.

ACUÑA, C; DE SOUZA, L. (Ed); GADINO, I; LEICHT, E; MUSSO, C; VAINER, D; VARELA; A; FINOZZI, A; OSIMANI, V; PASTORINO, S; PLADA, A. Aglomeración Maldonado - Punta del Este - San Carlos. Enfoques y propuestas hacia un modelo transformador. Montevideo: Udelar-Mosca Hnos. 2013.

ALEDO TUR, A.; MAZÓN MARTÍNEZ, T.; MANTECÓN, A. La insostenibilidad del turismo residencial". En D. LAGUNAS (Coord.). Antropología y turismo: claves culturales y disciplinares. México, D.F.: Plaza y Valdés, 2007, p. 185-208

ALCÁNTARA-CARRIÓ J; FONTÁN BOUZAS A; ALBARRACIN S; CORREA I; MONTOYA MONTES I \& MAHIQUES M. Geomorphological Coastal Classifications after Natural Processes and Human Disturbance. Journal of Oceanography and Marine Research, 2014, Vol. 2, N³.

ALMEIDA, J., COSTA, C. \& NUNES, F. A framework for conflict analysis in spatial planning for tourism. Tourism Management Perspectives, 2017, Vol. 24, p. 94-106.

ALONSO E. y BASSAGODA, M. J.La vegetación costera del SE uruguayo: ambientes y biodiversidad. Documentos de divulgación museo nacional de historia natural y antropología, Julio 2002, N5.

ALVAREZ LENZI, R. Fundación de poblados en el Uruguay. Historia de los problemas de la arquitectura nacional. Universidad de la República. Facultad de Arquitectura. Instituto de Historia de la arquitectura. Cátedra de historia de la arquitectura nacional, 1986, 1.8.1.

20 Relevamiento aerofotogramétrico 2017-18 a nivel nacional. 
ALVES, C. y GOSSO, C. Sedimentación dunar y vulnerabilidad a la erosión en la costa atlántica uruguaya. En C.GOSSO (Comp). Nuevas miradas a la problemática de los ambientes costeros. DIRAC - Facultad de Ciencias, 2014.

BARRANTES-REYNOLDS, M. The expansion of "real estate tourism" in coastal areas: Its behaviour and implications. Recreation and Society in Africa, Asia and Latin America. RASAALA, 2011, Vol. 2, № 1.

BERAZATEGUI, M.; HERNÁNDEZ, D. \& LOUREIRO, M. Análisis de DINAMA. componentes zoológicos en informes ambientales presentados ante DINAMA. En: Libro de resúmenes del II Congreso Uruguayo de Zoología. 9 al 14 diciembre de 2012. Facultad de Ciencias, UdelaR, 2012, 292 p. Disponible en: www.szu.org.uy/boletin/libro_resumenes_iicuz.pdf

BORETTO, G; ROUZAUT, S; CIOCCALE, M; GORDILLO, S. y BENÍTEZ, Y. Dinámica costera y antropización en playas uruguayas. Un análisis integrado para su conservación. Revista mexicana de ciencias geológicas, 2018, Vol. 35, №3, p. 291-306.

BRIDA, J.G; OSTI, L. \& SANTIFALLER, E. Second Homes and the Need for Policy Planning. Tourismos: an international multidisciplinary journal of tourism, 2011, Vol. 6, №1, p. 141-163.

BRUM, L. Gestión del patrimonio arqueológico en el litoral oeste del departamento de Maldonado (Uruguay), La investigación como práctica integral. Revista del Museo de La Plata. Sección Antropología, 2013, Vol. 13, N887, p. 417-428.

CAPANDEGUY, D; BERNARDI, R; GASTAMBIDE, F y DELGADO, M. Uruguay costa atlántica. Revisión sintética de formaciones territoriales y apertura de acciones urbanísticas de intervención ambientalmente sostenibles. Universidad de la república. Facultad de arquitectura, diseño y urbanismo llamado interno a presentación de proyectos de investigación 2015. Informe final, 2016.

CORTÉS CHÁVEZ, S. La capacidad de carga como herramienta para la ordenación sostenible del territorio. En: Boletín CF+S 42/43. Simposio Internacional Desarrollo, Ciudad y Sostenibilidad, La Serena, Chile, Octubre 2009.

DA CUNHA, N. y CAMPODÓNICO, R. Uruguay: hacia la noción de país turístico. Estudio histórico 1930 - 1955. Anuario IEHS, 2012, Vol. 27, p. 331-367

DE ÁLAVA, D. Incidencia del Proceso de Transformación Antrópico en el Sistema Costero La Paloma - Cabo Polonio, Rocha, Uruguay. Tesis de Maestría en Ciencias Ambientales, Facultad de Ciencias, UdelaR, Uruguay, 2007.

DÍAZ PELLICER, L. El turismo receptivo en Uruguay (1930 - 1986). Facultad de Ciencias Sociales, UdelaR. Programa de Historia Económica y Social. Unidad Multidisciplinaria. Documento On Line No 27, Febrero 2012.

ESCALERA-BRICEÑO, A; PALAFOX-MUÑOZ, A. \& ANGELES-VILLA, M. La producción del espacio turístico en la era del capitaloceno. Biblio3W, Revista Bibliográfica de Geografía y Ciencias Sociales, 2018, Vol. 23, Nº1254. 
GARCÍA DE FUENTES, A; JOUAULT, S. Y ROMERO, D. A Cartographic Representation of the Touristification of Cancún and the Yucatan Peninsula in the last 50 years. Investigaciones Geográficas, 2019, N¹00.

GIANOTTI, C.; GASCUE, A.; DEL PUERTO, L.; INDA, H. y E. VILLARMARZO. Archaeological heritage on the Atlantic coast of Uruguay: heritage policies and challenges for its management in coastal protected areas. En T. DAWSON, C. NIMURA, E. LÓPEZ-ROMERO, M.Y. DAIRE (Eds.). Public Archaeology and Climate Change. Oxbow books, 2017, p. 149-161.

GUDYNAS, E. Ecología, economía y ética del desarrollo sostenible. Montevideo: CLAES / Centro Latinoamericano de Ecología Social y D3E, 2004.

GUTIÉRREZ, O. Dinámica sedimentaria en la costa uruguaya. Un abordaje desde la geografía histórica y los s.i.g. para comprender las tendencias evolutivas vinculadas al cambio global. Universidad Internacional de Andalucía, 2016.

HADDAD, N; BRUDVIG, L, CLOBERT, J; DAVIES, K; GONZÁLEZ, A; HOLT, R; LOVEJOY, T; SEXTON, J; AUSTIN,M; COLLINS, C; COOK, W; DAMSCHEN, E; EWERS, R; FOSTER, B; JENKINS, C; KING, A; LAURANCE, W; LEVEY, D; MARGULES, C; MELBOURNE, B; NICHOLLS, A; ORROC, J; SONG, D and TOWNSHEND, J. Habitat fragmentation and its lasting impact on Earth's ecosystems, 2015, Vol. 1, No 2. e1500052 DOI: 10.1126 / sciadv.1500052

HARVEY, D. Mundos urbanos posibles. En: Ramos, A.M. (Ed). Lo Urbano en 20 autores contemporáneos. Barcelona: Ediciones UPCs, 2000, p. 177-198.

IBARRA MARINAS, D. y BELMONTE SERRATO, F. Comprendiendo el litoral: Dinámica y procesos. Universidad de Murcia. Editum, 2017.

IDR. Plan Local de Ordenamiento Territorial Lagunas Costeras. Intendencia Departamental de Rocha. Dirección de Ordenamiento territorial, 2010.

KLAPPENBACH, M; SCARABBINO, V. Al borde del mar. Colección Nuestra Tierra, Cuaderno No2. Editorial Nuestra Tierra. Montevideo, Uruguay, 1969.

LEFEBVRE, H. La producción del espacio. Madrid: Capitán Swing, 2013.

LIGRONE CIGANDA, A. Evaluación de impacto ambiental en Uruguay: revisión crítica y aportes desde la ecología. Tesis de maestría, Universidad de la República (Uruguay). Facultad de Ciencias, 2017.

LINDENMAYER, DB; FISCHER, J. Habitat Fragmentation and Landscape Change: An Ecological and Conservation Synthesis. Island Press, October 2006.

MCHARG, I. Proyectar con la Naturaleza. 1er Ed. 1969. Editorial Gustavo Gili SA Barcelona, 1992. 
MAZÓN, T. y ALEDO, A. "El dilema del turismo residencial: ¿turismo o desarrollo inmobiliario?" Turismo residencial y cambio social: nuevas perspectivas teóricas y empíricas. Universidad de Alicante, 2005, p: 13-30.

NAVARRO-JURADO, E; THIEL-ELLUL, D. \& ROMERO-PADILLA, Y. Pleasure peripheries: when tourism becomes real estate-tourism developmentalism. Boletín de la Asociación de Geógrafos Españoles, 2015, N67, p. 507-513.

PANARIO, D; GUTIÉRREZ, O. Dinámica y fuentes de sedimentos de las playas uruguayas. En: Bases para la conservación y el manejo de la costa uruguaya. En: Menafra, R; Rodríguez-Gallego, L; Scarabino, F; Conde, D. Vida Silvestre Uruguay, Montevideo, 2006.

PANARIO, D. Las playas uruguayas. Su dinámica, diagnóstico de situación actual y tendencias a mediano plazo. En: Domínguez, A.; Prieto, R. (Coord.). Perfil ambiental del Uruguay. Montevideo, Edinor, 2000, p. 111-125.

PEETERS, P., GÖSSLING, S., KLIJS, J., MILANO, C., NOVELLI, M., DIJKMANS, C., EIJGELAAR, E., HARTMAN, S., HESLINGA, J., ISAAC, R., MITAS, O., MORETTI, S., Nawijn, J., PAPP, B. and POSTMA, A. Research for TRAN Committee-Overtourism:. impact and possible policy responses. European Parliament, Directorate General for Internal Policies, Policy Department B: Structural and Cohesion Policies, Transport and Tourism. 2018

PERLES RIBES, J; RAMÓN RODRÍGUEZ, A; SUCH DEVESA, M. Second homes vs. residential tourism: A research gap. Turizam: međunarodni znanstveno-stručni časopis, 2018, Vol. 66, №1.

PINO ROJAS, K. Metropolización sobre zonas costeras: criterios de ordenamiento para la conservación de los sistemas ambientales. Actividad formativa equivalente a Tesis (AFE), para optar al Título de Magíster en Urbanismo. Universidad de Chile, 2018.

PIÑEIRA MANTIÑÁN, M. y SANTOS, X. Impact of Tourism on Coastal Towns: From Improvisation to Planification. The Open Urban Studies Journal, 2010, Vol. 3. p. 21-27.

PIÑEIRO, D. El caso de Uruguay. En: Soto Baquero, F. y Gómez, S. (Eds.). Dinámicas en el mercado de la tierra en américa latina. El informe final del proyecto fao, 2012.

PONTES, M.A; GARCÍA MARTÍN, R; MORENO MUÑOZ, D. Turismo, producción inmobiliaria y procesos espaciales: la difusión del modelo turístico español hacia Brasil. EUR, 2020, Vol. 46, №137, p. 135-156.

PROBIDES. Plan Director de la Reserva de Biosfera Bañados del Este. Uruguay. PROBIDES, 1999.

ROBAINA, M. A toda costa. Semanario Brecha. Edición 1658. 1/9/17, 2017. Accedido el 15/10/19.

RODRÍGUEZ, N. La participación de los legos en la conformación urbana. Un barrio cerrado para Bariloche, Argentina. Revista Uruguaya de Antropología y Etnografía, 2017, Vol.2, №2. 
RODRÍGUEZ MIRANDA, A; GALASO, P; GOINHEIX, S; MARTÍNEZ, C. Especializaciones productivas y desarrollo económico regional en Uruguay. Serie Documentos de Trabajo, DT 07/2017. Instituto de Economía, Facultad de Ciencias Económicas y Administración, Universidad de la República, Uruguay, 2017.

SCIANDRO, J. RABELLINO, C. La gobernanza de los espacios marítimo costeros en Uruguay: el rol de las autoridades locales y el estado central. En: Díaz Cano M. y Boon C.D. (Coord.) Gestión de Mares y Costas en Perspectiva Comparada. Escuela de Derecho de la Universidad Sergio Arboleda, Seccional Santa Marta, Colombia (en proceso de publicación), 2018.

SOUTULLO A, C CLAVIJO \& JA MARTÍNEZ-LANFRANCO (Eds.). Especies prioritarias para la conservación en Uruguay. Vertebrados, moluscos continentales y plantas vasculares. Montevideo: SNAP/ DINAMA/MVOTMA y DICYT/ MEC, 2013.

TONE. Texto Ordenado de Normas de la Edificación, Intendencia Departamental de Maldonado. Digesto departamental. IDM, 1998.

TROCHON GHISLIERI, Y. Punta del Este. El edén oriental. 1907-1997. Editorial Fin de Siglo, 2017.

URRUZOLA, J.P; ALEMÁN, L; LEICHT, E y LEITES, M. La forma de las ciudades uruguayas. MVOTMA - Junta de Andalucía. Imprimex S.A, 2011. D.L 355.596.

VAN NOORLOOS, F. Residential Tourism causing Land Privatization and Alienation: New pressures on Costa Rica's coasts. Development, 2011, Vol. 54, Nº1, p. 85-90.

VAN NOORLOOS, F. El turismo residencial: ¿Acaparamiento de tierras? Un proceso fragmentado de cambio socio-espacial, desplazamiento y exclusión. Opiniones en desarrollo. Programa Turismo Responsable. Albasud, investigación y comunicación para el desarrollo, agosto 2013, № 16 . 
